\title{
Comparisons of foveal thickness and slope after macular hole surgery with and without internal limiting membrane peeling
}

This article was published in the following Dove Press journal:

Clinical Ophthalmology

\section{Kouichi Ohta \\ Atsuko Sato \\ Nami Senda \\ Emi Fukui}

Department of Ophthalmology, Matsumoto Dental University, Nagano, Japan
Correspondence: Kouichi Ohta Department of Ophthalmology, Matsumoto Dental University, I780 Gobara, Hirooka, Shiojiri, Nagano 399-078I, Japan $\mathrm{Tel} / \mathrm{fax}+8 \mid 2635$ I 22। 0 Email ohta@po.mdu.ac.jp
Background: We have shown that the foveal contour was asymmetrical after idiopathic macular hole $(\mathrm{MH})$ closure by pars plana vitrectomy (PPV) with internal limiting membrane (ILM) peeling. The purpose of this study was to determine whether these morphological changes differ in eyes after PPV without ILM peeling.

Methods: Ten eyes of 10 patients that underwent PPV without ILM peeling and 12 eyes of 11 patients with ILM peeling were studied. The MH in all eyes was $<400 \mu \mathrm{m}$ in diameter. Six months after the PPV, the macular thickness and foveal slope around the closed MH were determined by spectral-domain optical coherence tomography. The thickness of the ganglion cell complex was measured by another spectral-domain optical coherence tomography instrument $>6$ months after the surgery.

Results: The mean parafoveal retinal thickness in the non-peeled group was $367.1 \mu \mathrm{m}$ in the nasal $(\mathrm{N}), 353.0 \mu \mathrm{m}$ in the temporal $(\mathrm{T}), 366.9 \mu \mathrm{m}$ in the superior $(\mathrm{S})$, and $357.3 \mu \mathrm{m}$ in the inferior (I) sectors. The T, S, and I sectors were significantly thicker than the corresponding sectors in the ILM peeled group ( $p=0.0008,0.003$, and 0.03 , respectively). The mean ganglion cell complex was thicker not only in the $\mathrm{N}$ sector but also in the $\mathrm{T}$ sector in the non-peeled group. The mean retinal slopes in the non-peeled group (N, 40.2 ${ }^{\circ}$; T, 37. $\left.6^{\circ} ; \mathrm{S}, 41.2^{\circ} ; \mathrm{I}, 39.5^{\circ}\right)$ were flatter than those in the peeled group $\left(\mathrm{N}, 52.3^{\circ} ; \mathrm{T}, 43.6^{\circ} ; \mathrm{S}, 50.8^{\circ} ; \mathrm{I}, 51.9^{\circ} ; p=0.009,0.09\right.$, 0.008 , and 0.017 , respectively).

Conclusion: The symmetrical fovea after MH surgery in the non-ILM peeled eyes indicates that the asymmetrical fovea after ILM peeling was probably due to the ILM peeling.

Keywords: idiopathic macular hole, foveal contour, internal limiting membrane, vitrectomy

\section{Introduction}

In 1991, Kelly and Wendel reported that idiopathic macular holes (MHs) can be closed by pars plana vitrectomy (PPV) with fluid-gas exchange. ${ }^{1}$ Thereafter, the surgical techniques for closing an $\mathrm{MH}$ have been modified. The success rate of $\mathrm{MH}$ has improved by combining the PPV with internal limiting membrane (ILM) peeling. ${ }^{2-4}$

However, an unusual postoperative appearance called a dissociated nerve fiber layer appearance was reported to develop after ILM peeling..$^{5-7}$ The ILM is the basement membrane of Müller cells and the inner barrier of the neural retina. There is good evidence that ILM peeling may cause mechanical damages to the inner retinal structures. We have shown that after MH surgery with ILM peeling, the parafoveal nasal retina was significantly thicker and the temporal retina was significantly thinner than the corresponding areas of the fellow eyes in the spectral-domain optical coherence tomography (SD-OCT) findings. ${ }^{8,9}$ In contrast, a spontaneous resolution of the $\mathrm{MH}$ 
resulted in a symmetrical foveal contour. ${ }^{10}$ To determine the cause of the asymmetrical foveal contour, it would be better to compare the retinal structure in eyes after vitrectomy with ILM peeling to that in eyes without ILM peeling.

Thus, the purpose of this study was to determine whether these morphological changes are present after MH surgery without ILM peeling.

\section{Methods}

This was a retrospective case series study carried out with the approval of the Institutional Review Board and Ethics Committee of Matsumoto Dental University, Shiojiri, Japan. The procedures used conformed to the tenets of the Declaration of Helsinki. The Institutional Review Board also approved the retrospective collection of the data from medical charts of the patients with and without diseases. A written informed consent was obtained for the surgery and for the use of data for research studies.

This study was a retrospective and nonrandomized study. The medical charts of 22 eyes of 21 Japanese patients with a full-thickness $\mathrm{MH}$ (6 men, 15 women) who had been treated at the Matsumoto Dental University Hospital between December 2008 and March 2017 were reviewed. Only eyes with an MH diameter of $<400 \mu \mathrm{m}$ in the SD-OCT images were studied. Patients with other ocular diseases, such as an epiretinal membrane (ERM), macular edema, rhegmatogenous retinal detachment, glaucoma, diabetic retinopathy, uveitis, and high pathological myopia, were excluded. Although ILM peeling had been done in all eyes with $\mathrm{MH}$ since 2008, we had stopped ILM peeling for eyes with $\mathrm{MH}<400 \mu \mathrm{m}$ since 2014 because of the high closure rates in smaller MHs without ILM peeling. ${ }^{11,12}$

\section{Surgical procedures}

The MHs were stage 2 in 13 eyes and stage 3 in 9 eyes. $^{13}$ The vitreoretinal surgery was performed with standard $23-\mathrm{G}$ $(n=4), 25-\mathrm{G}(\mathrm{n}=15)$, or $27-\mathrm{G}(\mathrm{n}=3)$ instruments by a single surgeon (KO). Phacoemulsification and placement of a posterior chamber intraocular lens were performed in all of the eyes. After core vitrectomy, triamcinolone acetonide (TA, Kenakolt-A; Bristol Pharmaceuticals KK, Tokyo, Japan; or MaQaid, Wakamoto Pharmaceuticals Co., Ltd, Tokyo, Japan) was injected into the vitreous cavity to make the vitreous gel more visible. After the creation of a posterior vitreous detachment (PVD), additional TA was injected to make the ILM more visible, by its deposition on the ILM. If the ILM was still not clearly visible, it was stained with $\sim 0.5 \mathrm{~mL}$ of $0.25 \%$ indocyanine green $\left(\mathrm{ICG}\right.$; Ophthagreen ${ }^{\circledR}$, Santen Pharmacy, Osaka, Japan) in 2 eyes or with $0.025 \%$
Brilliant Blue G (BBG; Brilliant Peel ${ }^{\circledR}$, Geuder, Heidelberg, Germany) in 4 eyes. A PVD was created by suction with the vitrectomy cutter in all eyes.

The ILM was grasped at the temporal raphe to avoid damaging the retinal nerve fiber layer. It was then peeled off for 2- to 4-disc areas. Then, fluid-air exchange was performed with the air pressure set at $35 \mathrm{mmHg}$. At the completion of surgery, $20 \%$ sulfur hexafluoride $\left(\mathrm{SF}_{6}\right)$ was injected for a gas tamponade. The patients were instructed to remain in a prone position for at least 7 days.

\section{Spectral-domain optical coherence tomography}

SD-OCT examinations were performed before and at 6 months after the PPV with the Spectralis HRA+OCT instrument (Heidelberg Engineering, Heidelberg, Germany). The macular thickness and volume were obtained with the volume scan mode of the OCT instrument as described in detail by Ohta et al. ${ }^{8,9}$ The mean full thickness of the fovea within a 1-mm diameter circle, the parafoveal area within annulus diameters of 1 and $3 \mathrm{~mm}$, and the perifoveal area within annulus diameters of 3 and $6 \mathrm{~mm}$ were automatically measured with the retinal thickness map analysis protocol of the Spectralis (ver. 4c). ${ }^{14}$ One eye in each group was excluded from analysis because these were bilateral cases. Another fellow eye without ILM peeling was excluded due to a thickened retina caused by an ERM.

To evaluate the effect of the surgery on the retinal layers, SD-OCT examinations were performed at least 6 months after the PPV with the RS-3000 Advance OCT (NIDEK, Aichi, Japan). To obtain images of the macular ganglion cell complex (GCC), the raster scanning was performed over a $9 \times 9 \mathrm{~mm}^{2}$ area centered on the fovea with a scan density of 512 A-scans (horizontal) $\times 128$ B-scans (vertical). The GCC thickness was measured between the ILM and outer boundary of the inner plexiform layer by the embedded program. The RS-3000 OCT provides a macular map based on the glaucoma analysis chart ( $\mathrm{G}$ Chart). The peripheral concentric areas were divided into eight subfields centered on the fovea: superonasal, inferonasal, superotemporal, and inferotemporal for the parafoveal (4.5 mm diameter) and perifoveal $(9.0 \mathrm{~mm}$ diameter) subfields. Areas within a $1.5 \mathrm{~mm}$ diameter of the foveal center were excluded.

The foveal slope was measured with the ImageJ (National Institutes of Health) software by two masked examiners as described in detail by Ohta et al. ${ }^{15}$ The horizontal and vertical images obtained by the Spectralis HRA+OCT centered on the fovea in the cross-hair mode $\left(30^{\circ}\right)$ were evaluated. In brief, the foveal slope was expressed as the angle (in degrees) 
formed by the flat retinal pigment epithelium (RPE) and a line running tangentially along the borders of the closed $\mathrm{MH}$. The angle of foveal slope was defined as the angle between a virtual line parallel to the ellipsoid zone of the photoreceptors except in the region of the foveal bulge or the RPE and a virtual line tangential to the foveal wall.

\section{Statistical analyses}

The results are expressed as the means \pm SDs. The data were analyzed with the IBM SPSS Statistics software (version 21, IBM Corp., Armonk, New York, USA). The best-corrected visual acuity (BCVA) was measured with a Landolt C chart, and the decimal values were converted to logarithm of the minimal angle of resolution ( $\log M A R)$ units. The significance of the differences in the pre- and postoperative BCVAs was determined by paired $t$-tests. The significance of the differences in the pre- and postoperative retinal thickness, GCC thickness, and foveal slopes was determined by unpaired $t$-tests. The Bonferroni correction was used to adjust the significance of the differences for continuous data of each sector of the retinal thickness, GCC thickness, and slopes. A difference was taken to be statistically significant when the $p$-value was $<0.05$.

\section{Results}

\section{Demographics and BCVA of all eyes}

The clinical characteristics of all of the eyes are summarized in Table 1. There were no significant differences in the values of the ocular parameters between the ILM peeled and ILM not peeled groups. The $\mathrm{MH}$ was closed in all the eyes after the first operation. The postoperative BCVA in the ILM peeled

Table I Demography and clinical characteristics of eyes undergoing pars plana vitrectomy

\begin{tabular}{llll}
\hline & $\begin{array}{l}\text { With ILM } \\
\text { peeling } \\
\text { Mean } \pm \text { SD }\end{array}$ & $\begin{array}{l}\text { Without } \\
\text { ILM peeling } \\
\text { Mean } \pm \text { SD }\end{array}$ & p-value \\
\hline Eyes & 12 & 10 & \\
Men, women & $3(4$ eyes), 8 & 3,7 & \\
Age (years) & $66.0 \pm 4.9$ & $69.1 \pm 5.7$ & 0.19 \\
Axial length (mm) & $23.8 \pm 1.0$ & $23.5 \pm 1.0$ & 0.53 \\
$\begin{array}{l}\text { Macular hole }(\mu \mathrm{m}) \\
\quad \text { Minimal }\end{array}$ & $267.7 \pm 78.7$ & $271.2 \pm 78.7$ & 0.86 \\
$\quad$ Basal & $324.7 \pm 72.4$ & $315.9 \pm 1 \mathrm{II} .1$ & 0.83 \\
$\begin{array}{l}\text { Macular hole stage } \\
\text { 2:3 (eyes) }\end{array}$ & $6: 6$ & & \\
BCVA (logMAR) & & $7: 3$ & 0.90 \\
$\quad \begin{array}{l}\text { Baseline } \\
\text { 6 months }\end{array}$ & $0.40 \pm 0.16$ & $0.38 \pm 0.16$ & 0.80 \\
\hline
\end{tabular}

Note: $* * p<0.0000$ I.

Abbreviations: BCVA, best-corrected visual acuity; ILM, internal limiting membrane; logMAR, logarithm of minimum angle of resolution. group was $0.08 \pm 0.09 \log$ MAR units which was significantly better than the preoperative BCVA of $0.40 \pm 0.16 \log$ MAR units $(p<0.00001)$. The BCVA in the eyes without ILM peeling improved significantly from $0.38 \pm 0.16 \log$ MAR units to $-0.045 \pm 0.11 \log$ MAR units $(p<0.00001)$. There was no significant difference in the postoperative BCVA between the two groups.

\section{Comparisons of mean retinal thickness in eyes with and without ILM peeling}

The mean central macula was significantly thicker in the ILM peeled eyes $(300.1 \pm 19.2 \mu \mathrm{m})$ than in the fellow eyes (257.5 $\pm 21.8 \mu \mathrm{m} ; p=0.0001$; Table 2$)$. In contrast, there was no significant difference in the macular thickness between the MH eyes without ILM peeling and the fellow eyes.

The mean thicknesses of the nasal and inferior parafoveal sectors in the eyes with ILM peeling were significantly thicker than the corresponding sectors of the fellow eyes ( $p=0.0002$ and $p=0.02$, respectively). However, the mean thickness in the temporal sector was thinner than that in fellow eye. In contrast, the mean parafoveal retinal thickness in all of the sectors in the eyes without ILM peeling was significantly thicker than the corresponding sectors in the fellow eyes. There were no significant differences in the perifoveal thicknesses between the eyes with ILM peeling and the fellow eyes. On the other hand, the mean perifoveal thicknesses in the operated eyes without peeling were larger than those in fellow ones in all sectors.

The central retina was thinner in the ILM peeled eyes than the non-peeled eyes but the difference was not significant (Table 3). The parafoveal retina was significantly thicker in all sectors in the eyes without ILM peeling than in eyes with ILM peeling. There were significant differences in temporal, superior, and inferior parafoveal sectors and temporal and superior perifoveal sectors. In the ILM peeling group, the mean parafoveal thickness in the nasal sector was significantly higher than that in other sectors. The parafoveal temporal retina was significantly thinner than that of the other sectors. In contrast, the retinal thicknesses were equally increased in all four sectors in the eyes without ILM peeling. The total retinal thicknesses at 6 months after the surgery are shown as color maps in eyes with MH surgery with (Figure 1A) and without (Figure 2A) ILM peeling.

\section{Comparison of mean parafoveal thickness of GCC after successful MH surgery with and without ILM peeling}

The mean parafoveal GCC in the eyes with a closed MH with ILM peeling were thinner than those without ILM peeling 
Table 2 Comparison of the mean retinal thickness of postoperative eyes after macular hole surgery at 6 months and corresponding fellow eyes $(\mu \mathrm{m}$, mean $\pm \mathrm{SD})$

\begin{tabular}{|c|c|c|c|c|c|c|}
\hline & \multicolumn{3}{|c|}{ With ILM peeling $(n=I I)$} & \multicolumn{3}{|c|}{ Without ILM peeling $(n=8)$} \\
\hline & Operated eye & Fellow eye & $p$-value & Operated eye & Fellow eye & $p$-value \\
\hline Central retinal thickness & $300.1 \pm 19.2$ & $257.5 \pm 21.8$ & 0.0001 & $278.7 \pm 26.6$ & $276.0 \pm 25.6$ & 0.64 \\
\hline \multicolumn{7}{|l|}{ Parafovea } \\
\hline Nasal & $359.2 \pm 9.0$ & $336.9 \pm 13.6$ & 0.0002 & $366.3 \pm 23.8$ & $346.3 \pm 12.4$ & 0.02 \\
\hline Temporal & $316.2 \pm 7.1$ & $322.3 \pm 12.1$ & 0.27 & $354.4 \pm 25.6$ & $333.5 \pm 11.1$ & 0.03 \\
\hline Superior & $342.4 \pm 11.9$ & $331.4 \pm 14.0$ & 0.09 & $368.0 \pm 27.8$ & $341.6 \pm 10.4$ & 0.009 \\
\hline Inferior & $339.7 \pm 10.1$ & $328.1 \pm 12.4$ & 0.02 & $358.9 \pm 22.2$ & $339.4 \pm 9.9$ & 0.03 \\
\hline \multicolumn{7}{|l|}{ Perifovea } \\
\hline Nasal & $314.9 \pm 15.5$ & $304.5 \pm 18.8$ & 0.24 & $327.7 \pm 26.6$ & $310.0 \pm 16.4$ & 0.04 \\
\hline Temporal & $283.4 \pm 10.0$ & $274.9 \pm 12.0$ & 0.14 & $305.3 \pm 24.0$ & $282.6 \pm 10.8$ & 0.02 \\
\hline Superior & $304.4 \pm 12.0$ & $290.0 \pm 19.3$ & 0.11 & $314.6 \pm 22.7$ & $291.0 \pm 12.6$ & 0.003 \\
\hline Inferior & $288.1 \pm 16.3$ & $275.7 \pm 16.6$ & 0.13 & $301.9 \pm 21.4$ & $285.5 \pm 12.6$ & 0.07 \\
\hline
\end{tabular}

Notes: One eye in each group was excluded as bilateral cases. One eye without ILM peeling was excluded due to thick retina caused by epiretinal membrane. Abbreviation: ILM, internal limiting membrane.

(Table 4). More specifically, there were significant differences in the temporal superior sector and the temporal inferior sector ( $p=0.008$ and $p=0.02$, respectively). In contrast, there were no significant differences between the thicknesses of the nasal superior and nasal inferior sectors between the eyes with and without ILM peeling. The GCC thicknesses are shown as color maps in Figures 1B and 2B.

\section{Comparison of foveal slopes in eyes with and without ILM peeling}

In the eyes with an MH treated with ILM peeling, the mean angles of the foveal slope of the fellow eyes were $35.3^{\circ} \pm 6.7^{\circ}$ in the nasal, $33.7^{\circ} \pm 6.9^{\circ}$ in the temporal, $34.2^{\circ} \pm 4.8^{\circ}$ in the

Table 3 Comparison of the mean retinal thickness of postoperative eyes after macular hole surgery at 6 months with and without ILM peeling $(\mu \mathrm{m}$, mean $\pm \mathrm{SD})$

\begin{tabular}{llll}
\hline & $\begin{array}{l}\text { With ILM } \\
\text { peeling }(\mathbf{n}=\mathbf{1 2})\end{array}$ & $\begin{array}{l}\text { Without ILM } \\
\text { peeling }(\mathbf{n}=\mathbf{1 0})\end{array}$ & -value \\
\hline $\begin{array}{l}\text { Central retinal } \\
\text { thickness }\end{array}$ & $302.8 \pm 20.6$ & $282.1 \pm 27.7$ & 0.07 \\
Parafovea & & & \\
$\quad$ Nasal & $359.7 \pm 8.7^{\mathrm{a}}$ & $367.1 \pm 20.2$ & 0.30 \\
$\quad$ Temporal & $317.4 \pm 8.0^{\mathrm{b}}$ & $353.0 \pm 23.2$ & 0.0008 \\
Superior & $341.2 \pm 12.1$ & $366.9 \pm 23.3$ & 0.008 \\
Inferior & $340.3 \pm 9.8$ & $357.3 \pm 20.4$ & 0.03 \\
Perifovea & & & \\
$\quad$ Nasal & $313.4 \pm 15.6$ & $330.2 \pm 22.3$ & 0.06 \\
$\quad$ Temporal & $282.2 \pm 10.4$ & $303.6 \pm 20.9$ & 0.01 \\
Superior & $301.9 \pm 14.2$ & $319.2 \pm 20.9$ & 0.04 \\
Inferior & $286.5 \pm 16.5$ & $299.6 \pm 18.4$ & 0.10 \\
\hline
\end{tabular}

Notes: ${ }^{T}$ The mean retinal thickness in nasal parafoveal retina was significantly larger than that in temporal $(p=0.000)$, superior $(p=0.00)$, and inferior $(p=0.00)$ ones. ${ }^{\circ}$ The mean retinal thickness in temporal parafoveal retina was significantly less than that in nasal $(p=0.000)$, superior $(p=0.00)$, and inferior $(p=0.00)$ ones.

Abbreviation: ILM, internal limiting membrane. superior, and $35.0^{\circ} \pm 6.2^{\circ}$ in the inferior sides of the foveal pit (Table 5). The corresponding mean angles at 6 months after the surgery with ILM peeling were $52.3^{\circ} \pm 6.6^{\circ}, 43.6^{\circ} \pm 9.0^{\circ}$, $50.8^{\circ} \pm 9.8^{\circ}$, and $51.9^{\circ} \pm 10.7^{\circ}$, respectively. All but the temporal angle were significantly larger than those of the corresponding sectors in the fellow eyes. In contrast, the mean angles of the foveal slope in all sectors in the closed $\mathrm{MH}$ without ILM peeling were also steeper than those in corresponding sectors of the fellow eyes. The mean angles of the foveal slope in the closed MH eyes after ILM peeling were significantly steeper than those in eyes without ILM peeling except on the temporal side. The preoperative and postoperative horizontal SD-OCT images are shown in Figure 1C and D (with ILM peeling) and Figure 2C and D (without ILM peeling).

\section{Discussion}

To the best of our knowledge, this is the first study to compare the retinal thickness and foveal slope around the fovea after successful MH surgery with and without ILM peeling. Earlier, we reported that the parafoveal thicknesses were asymmetrical in the SD-OCT images in eyes after ILM peeling. ${ }^{8,9}$ Quantitative analyses showed that the parafoveal retina was thicker in all sectors except the temporal sector at 6 months after the MH surgery with ILM peeling. ${ }^{9}$ In this study, the mean thickness of the parafoveal retina in eyes with ILM peeling was similar to our previous reports, ${ }^{8,9}$ ie, thicker nasal and thinner temporal retina. In contrast to the ILM peeling group, an asymmetry was not observed in the non-ILM peeling group. Although Kumagai et al reported similar results, the sizes of $\mathrm{MH}$ were not reported. ${ }^{16}$ Based on a relatively large number of eyes, they found that thinning of the temporal retina and thickening of the nasal retina were observed not only in MH but also in ERM after ILM peeling. On the 


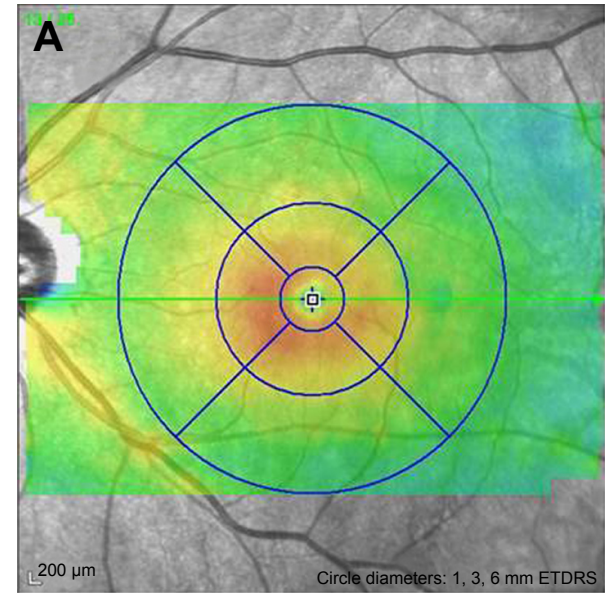

B
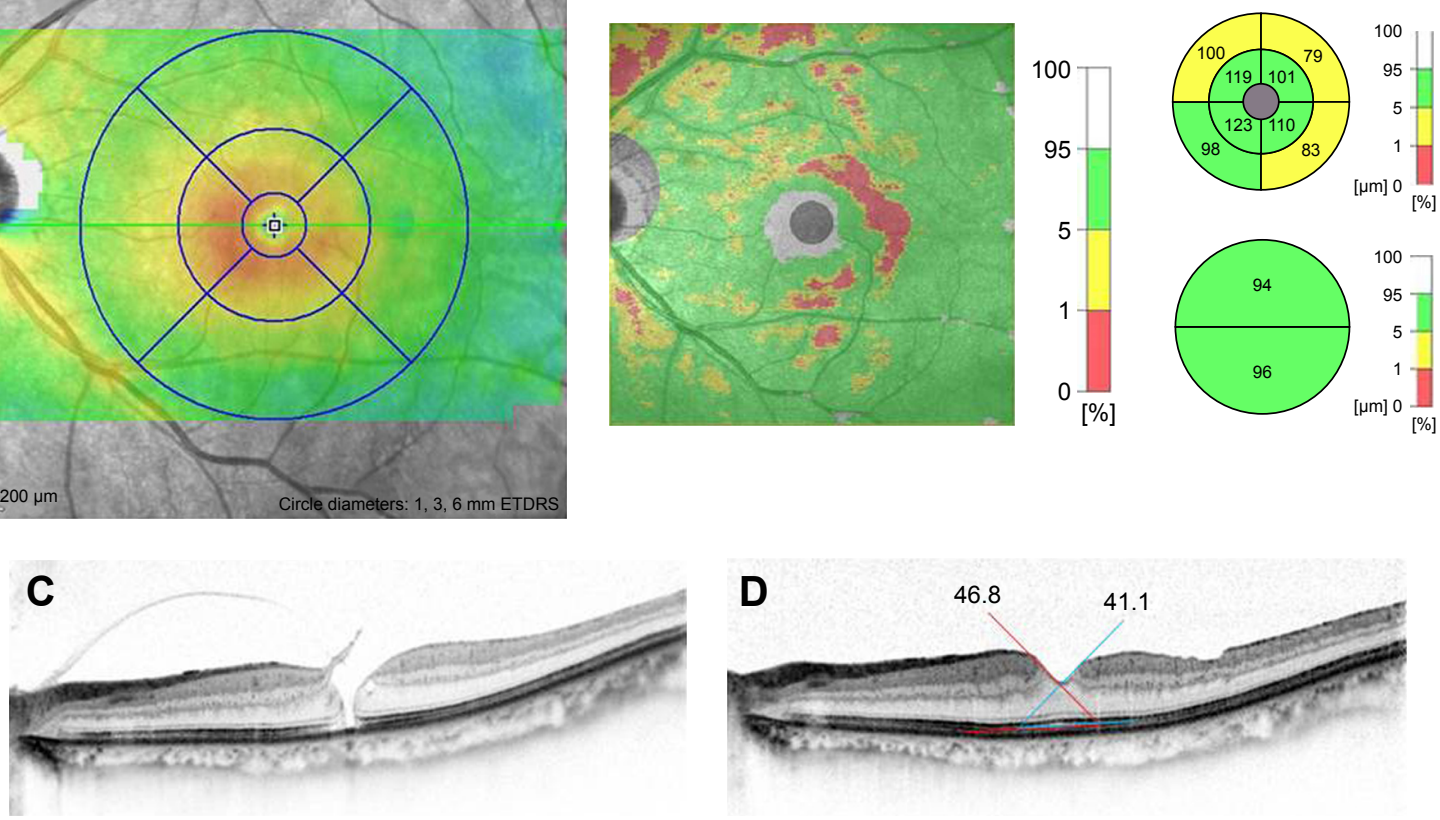

Figure I SD-OCT images of a 7/-year-old man with a stage $2 \mathrm{MH}$ who underwent PPV with peeling of the ILM.

Notes: The BCVA improved from 20/30 preoperatively to 20/16 at 6 months postoperatively. The total retinal thickness is shown as a color map obtained by Spectralis HRA+OCT (A) at 6 months. The thickness of the GCC is also shown and analyzed by RS-3000 (B) at 6 months after the surgery. A preoperative horizontal SD-OCT image is shown (C). The angle between the flat line of RPE and the slope around the closed MH was manually measured with Imagej (D; horizontal image). The angles are shown as the degrees between the red lines (nasal side) and the blue lines (temporal side).

Abbreviations: BCVA, best-corrected visual acuity; GCC, ganglion cell complex; ILM, internal limiting membrane; MH, macular hole; PPV, pars plana vitrectomy; RPE, retinal pigment epithelium; SD-OCT, spectral-domain optical coherence tomography.

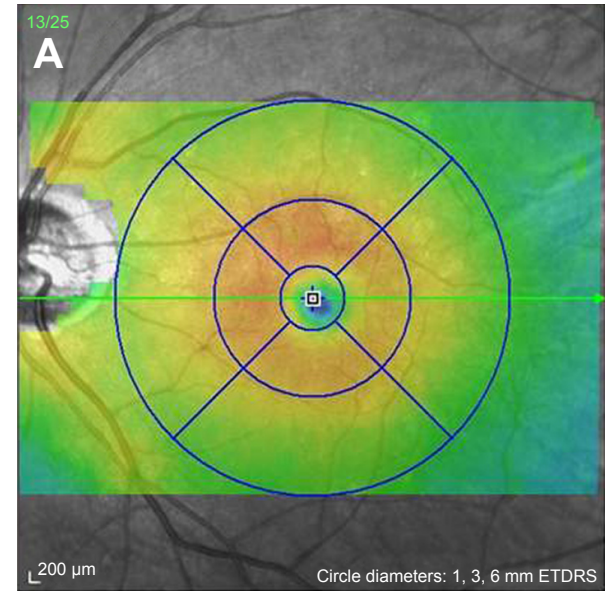

B
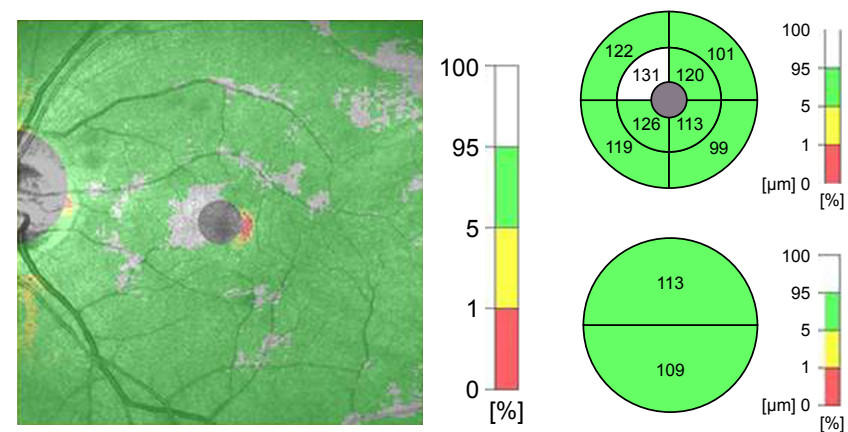

C

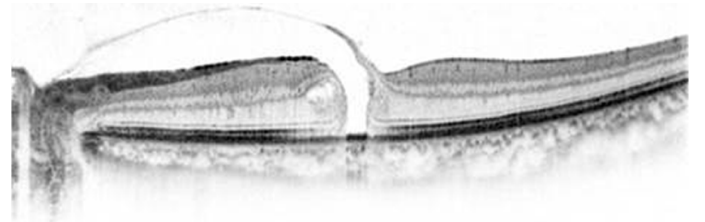

D

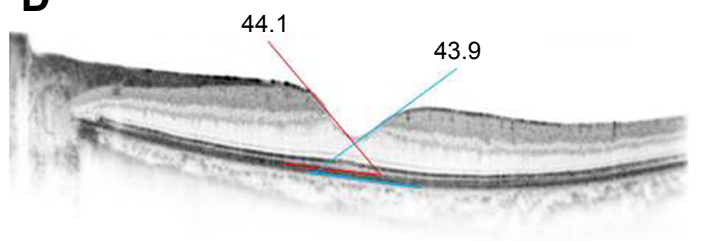

Figure 2 SD-OCT images of a 62-year-old woman with stage $3 \mathrm{MH}$ after PPV without peeling of the ILM.

Notes: The BCVA improved from 20/32 at baseline to 20/16 at 6 months postoperatively. The total retinal thickness is shown as a color map obtained by Spectralis HRA+OCT (A) at 6 months. The thickness of the GCC was analyzed by RS-3000 (B) at 6 months after the surgery. A preoperative horizontal SD-OCT image is shown (C). The angle between the flat line of the RPE and the slope around the closed MH was manually measured with ImageJ (D; horizontal image). The angles are shown as the degrees between red lines (nasal side) and blue lines (temporal side).

Abbreviations: BCVA, best-corrected visual acuity; GCC, ganglion cell complex; ILM, internal limiting membrane; MH, macular hole; PPV, pars plana vitrectomy; RPE, retinal pigment epithelium; SD-OCT, spectral-domain optical coherence tomography. 
Table 4 Comparison of the mean parafoveal GCC of postoperative eyes after macular hole surgery with ILM peeling and without ILM peeling $(\mu \mathrm{m}$, mean $\pm \mathrm{SD})$

\begin{tabular}{llll}
\hline & $\begin{array}{l}\text { With ILM } \\
\text { peeling }\end{array}$ & $\begin{array}{l}\text { Without ILM } \\
\text { peeling }\end{array}$ & p-value \\
\hline Nasal superior & $117.9 \pm 10.2$ & $128.5 \pm 17.0$ & 0.11 \\
Nasal inferior & $119.7 \pm 8.2$ & $123.7 \pm 15.8$ & 0.49 \\
Temporal superior & $98.3 \pm 8.9^{*}$ & $116.8 \pm 16.3$ & 0.008 \\
Temporal inferior & $101.0 \pm 9.9^{*}$ & $115.9 \pm 15.2$ & 0.02 \\
\hline
\end{tabular}

Notes: $*=0.00$ I; between nasal superior vs temporal superior and nasal inferior vs temporal inferior with the ILM peeling group. There was no significant difference between the with and without ILM peeling groups, although the GCC thickness after surgery was thicker in the nasal lesion and thinner in the temporal one compared with the fellow eye (data not shown). There was no significant difference in the perifoveal lesions (data not shown).

Abbreviations: GCC, ganglion cell complex; ILM, internal limiting membrane.

other hand, the parafoveal macular thicknesses were similar after PPV without ILM peeling for retinal detachment. ${ }^{17}$ The symmetrical parafoveal macular thickness without ILM peeling is probably not disease specific.

In an earlier study, we manually measured the thickness of the retinal layers after MH surgery with ILM peeling manually. ${ }^{9}$ We found that the ganglion cell layer and internal plexiform layer, which are major parts of the GCC, contributed to the thickening of nasal retina and thinning of the temporal one. In this study, our results showed clearly a thinning of the GCC in the temporal area after ILM peeling. A significant thinning of the temporal area was found only in eyes with ILM peeling as has been reported. ${ }^{18}$ This indicates that ILM peeling can induce significant thinning of the GCC in the temporal areas.

After MH surgery, the mean angles of the closed MHs increased compared with those of fellow eyes. We have shown similar results based on a relatively larger number of the eyes. ${ }^{15}$ In addition, this is the first report to compare the mean angles of foveal slope around the closed $\mathrm{MH}$ with or without ILM peeling. Interestingly, there were significant differences in the mean angles between eyes with and without ILM peeling. In other words, the retinal slope around closed MHs after surgery with ILM peeling was steeper than that without it. In addition, the retinal slope was flattest in the temporal side after ILM peeling, although there was no significant difference probably because of the small number of eyes.

The foveal slopes of normal control eyes and of the fellow eyes were $\sim 30^{\circ}$ with differences among the slopes of the nasal, temporal, superior, and inferior quadrants not significant. Thus, the foveal contour around fovea was symmetrical. ${ }^{15}$ In the operated eyes, the mean foveal slope was significantly steeper than that in fellow eyes, and the steepest slope was found in the nasal quadrant. The mean parafoveal retinal thickness was thinnest in the temporal quadrant which corresponds to the site of the flattest foveal slope.

Based on these results, we concluded that the asymmetrical parafoveal retinal thickness and the steepening of the foveal slope after MH surgery are strongly associated with ILM peeling. The exact mechanism causing the increased steepness of the foveal slope after the MH surgery with ILM peeling was not determined.

Kim et al found an asymmetric elongation of the foveal tissue after MH surgery. The horizontal inter-outer plexiform layer distances were longer than the vertical ones. ${ }^{19}$ They suspected that the stretching of tissues due to dragging toward the peripheary of the macula may play a role. Recently, a macular displacement after MH surgery with ILM peeling was excellently analyzed by Pak et al. ${ }^{20}$ The macula was displaced centripetally, nasally, and slightly inferiorly after surgery. They suggested that the contraction force by the retinal nerve fiber layer displaced the retina nasally. It was suggested that a contraction of the ganglion cells axon is evoked by ILM peeling, resulting in the movement of the retinal tissue. Because the nerve fibers are anchored to the lamina cribrosa, contraction moves the retina toward the disc. Because these speculations are about foveal displacements, the exact mechanism causing the thicker nasal retina and thinner temporal one may not be the same.

However, it is known that the Müller cell cone, which is an inverted cone-shaped zone of specialized Müller cells

Table 5 Comparison of the mean retinal slope of postoperative eyes after macular hole surgery with ILM peeling and without ILM peeling $\left({ }^{\circ}\right.$, mean $\left.\pm \mathrm{SD}\right)$

\begin{tabular}{|c|c|c|c|c|c|c|c|}
\hline & \multicolumn{3}{|c|}{ With ILM peeling } & \multicolumn{3}{|c|}{ Without ILM peeling } & \multirow{2}{*}{$\frac{\text { With vs without }}{p \text {-value }}$} \\
\hline & Operated eye & Fellow eye & $p$-value & Operated eye & Fellow eye & $p$-value & \\
\hline Nasal & $52.3 \pm 6.6$ & $35.3 \pm 6.7$ & 0.0003 & $40.2 \pm 7.9$ & $30.3 \pm 3.3$ & 0.008 & 0.009 \\
\hline Temporal & $43.6 \pm 9.0$ & $33.7 \pm 6.9$ & 0.07 & $37.6 \pm 7.0$ & $30.3 \pm 5.2$ & 0.04 & 0.09 \\
\hline Superior & $50.8 \pm 9.8$ & $34.2 \pm 4.8$ & 0.005 & $41.2 \pm 7.6$ & $31.2 \pm 4.9$ & 0.006 & 0.008 \\
\hline Inferior & $51.9 \pm 10.7$ & $35.0 \pm 6.2$ & 0.004 & $39.5 \pm 7.9$ & $33.1 \pm 5.2$ & 0.09 & 0.017 \\
\hline
\end{tabular}

Abbreviation: ILM, internal limiting membrane. 
that form the base of the retina, serves as a plug to bind the photoreceptors together in the fovea and supports the fovea structurally. ${ }^{21,22}$

Our results showed that the marked changes of the foveal contour after MH surgery occurred only in eyes with ILM peeling. Based on a meta-analysis, ILM peeling achieved significantly higher anatomical success with reduced need for additional surgical interventions. ${ }^{23}$ ILM peeling was also found to be highly cost effective. ${ }^{23}$ However, the functional deterioration of the retinas remains controversial. ${ }^{7,24,25}$ A decrease in retinal sensitivity in eyes with ILM peeling has been shown by microperimetry. ${ }^{26}$ Baba et al reported a reduced retinal sensitivity by MP-1 microperimetry associated with thinner GCC. ${ }^{18}$ Although we compared the paracentral retinal sensitivity based on Humphrey perimetry 30-2 and 10-1 program, there was no significant difference between the two groups (data not shown).

The dye for ILM staining might be involved in the asymmetrical retinal thickness after ILM peeling. ICG is considered to be toxic, ${ }^{27}$ and $\mathrm{BBG}$ has been reported to have fewer adverse effects on retinal cells. ${ }^{28}$ However, we cannot analyse this because of the small number of eyes. The size of the ILM peeled area may affect the contour after surgery. ${ }^{29}$ In this study, the ILM peeling was done for about 2 disc areas in almost all cases - the size was estimated during surgery. Further study is needed to estimate the exact ILM peeled area and the contour.

There are limitations to this study. First, this was a retrospective study and the number of patients studied was small, which may have affected the reliability of the statistical analyses. Second, the analyses were based on the findings at $\geq 6$ months after the MH surgery. Thus, our results do not reflect the long-term outcomes. Third, a single surgeon performed all of the surgeries which may limit broad conclusions. Further prospective studies are necessary to confirm our results.

\section{Conclusion}

The symmetrical fovea after MH surgery in the non-ILM peeled eyes indicates that the asymmetrical fovea may be due to the ILM peeling. Further studies including the association with retinal sensitivity and metamorphopsia are needed.

\section{Acknowledgment}

We thank Professor Emeritus Duco Hamasaki of the Bascom Palmer Eye Institute, University of Miami, FL, USA, for editing the manuscript.

\section{Disclosure}

The authors report no conflicts of interest in this work.

\section{References}

1. Kelly NE, Wendel RT. Vitreous surgery for idiopathic macular holes: results of a pilot study. Arch Ophthalmol. 1991;109(5):654-659.

2. Brooks HL Jr. Macular hole surgery with and without internal limiting membrane peeling. Ophthalmology. 2000;107(10):1939-1948.

3. Christensen UC, Kroyer K, Sander B, et al. Value of internal limiting membrane peeling in surgery for idiopathic macular hole stage 2 and 3 : a randomized clinical trial. Br J Ophthalmol. 2009;93(8):1005-1015.

4. Lois N, Burr J, Norrie J, et al. Internal limiting membrane peeling versus no peeling for idiopathic full-thickness macular hole: a pragmatic randomized controlled trial. Invest Ophthalmol Vis Sci. 2011;52(3): $1586-1592$.

5. Tadayoni R, Paques M, Massin P, Mouki-Benani S, Mikol J, Gaudric A. Dissociated optic nerve fiber layer appearance of the fundus after idiopathic epiretinal membrane removal. Ophthalmology. 2001;108(12): 2279-2283.

6. Ito Y, Terasaki H, Takahashi A, Yamakoshi T, Kondo M, Nakamura M. Dissociated optic nerve fiber layer appearance after internal limiting membrane peeling for idiopathic macular holes. Ophthalmology. 2005; 112(8):1415-1420.

7. Mitamura Y, Ohtsuka K. Relationship of dissociated optic nerve fiber layer appearance to internal limiting membrane peeling. Ophthalmology. 2005; 112(10): 1766-1770.

8. Ohta K, Sato A, Fukui E. Asymmetrical thickness of parafoveal retina around surgically closed macular hole. Br J Ophthalmol. 2010;94(11): $1545-1546$.

9. Ohta K, Sato A, Fukui E. Retinal thickness in eyes with idiopathic macular hole after vitrectomy with internal limiting membrane peeling. Graefes Arch Clin Exp Ophthalmol. 2013;251(5):1273-1279.

10. Inoue M, Arakawa A, Yamane S, Watanabe Y, Kadonosono K. Longterm outcome of macular microstructure assessed by optical coherence tomography in eyes with spontaneous resolution of macular hole. Am J Ophthalmol. 2012;153(4):687-691.

11. Ullrich S, Haritoglou C, Gass C, Schaumberger M, Ulbig MW, Kampik A. Macular hole size as a prognostic factor in macular hole surgery. Br J Ophthalmol. 2002;86(4):390-393.

12. Tadayoni R, Gaudric A, Haouchine B, Massin P. Relationship between macular hole size and the potential benefit of internal limiting membrane peeling. Br J Ophthalmol. 2006;90(10):1239-1241.

13. Gaudric A, Haouchine B, Massin P, Paques M, Blain P, Erginay A. Macular hole formation: new data provided by optical coherence tomography. Arch Ophthalmol. 1999;117(6):744-751.

14. Grover S, Murthy RK, Brar VS, Chalam KV. Normative data for macular thickness by high-definition spectral-domain optical coherence tomography (Spectralis). Am J Ophthalmol. 2009;148(2):266-271.

15. Ohta K, Sato A, Senda N, Fukui E. Asymmetrical steepening of the foveal contour after macular hole surgery with internal limiting membrane peeling. Jpn J Opthalmol. 2016;60(5):388-394.

16. Kumagai K, Ogino N, Furukawa M, et al. Retinal thickness after vitrectomy and internal limiting membrane peeling for macular hole and epiretinal membrane. Clin Ophthalmol. 2012;6:679-688.

17. Ohta K, Sato A, Fukui E. Comparison of parafoveal retinal thickness in eyes with idiopathic macular hole to that with rhegmatogenous retinal detachment after vitrectomy. $J$ Clin Experiment Ophthalmol. 2012;3:1.

18. Baba T, Hagiwara A, Sato E, Arai M, Oshitari T, Yamamoto S. Comparison of vitrectomy with brilliant blue G or ICG on retinal microstructure and function of eyes with macular hole. Ophthalmology. 2012; 119(12):2609-2615.

19. Kim JH, Kang SW, Park DY, Kim SJ, Ha HS. Asymmetric elongation of foveal tissue after macular hole surgery and its impact on metamorphopsia. Ophthalmology. 2012;119(10):2133-2140. 
20. Pak KY, Park KH, Kim KH, et al. Topographic changes of the macula after closure of idiopathic macular hole. Retina. 2017;37(4):667-672.

21. Yamada E. Some structural features of the fovea centralis in the human retina. Arch Ophthalmol. 1969;82(2):151-159.

22. Gass JD. Muller cell cone, an overlooked part of anatomy of the fovea centralis: hypotheses concerning its role in the pathogenesis of macular hole and foveomacular retinoschisis. Arch Ophthalmol. 1999;117(6): 821-823.

23. Cornish KS, Lois N, Scott NW, et al. Vitrectomy with internal limiting membrane peeling versus no peeling for idiopathic full-thickness macular hole. Ophthalmology. 2014;121(3):649-655.

24. Haritoglou C, Ehrt O, Gass CA, Kristin N, Kampik A. Paracentral scotoma: a new finding after vitrectomy for idiopathic macular hole. Br J Ophthalmol. 2001;85(2):231-233.
25. Haritoglou C, Gass CA, Schaumberger M, Gandorfer A, Ulbig MW, Kampik A. Long-term follow-up after macular hole surgery with internal limiting membrane peeling. Am J Opthalmol. 2002;134(5):661-666.

26. Tadayoni R, Svorenova I, Erginay A, Gaudric A, Massin P. Decreased retinal sensitivity after internal limiting membrane peeling for macular hole surgery. Br J Ophthalmol. 2012;96(12):1513-1516.

27. Sippy BD, Engelbrecht NE, Hubbard GB, et al. Indocyanine green effect on cultured human retinal pigment epithelial cells: implication for macular hole surgery. Am J Ophthalmol. 2001:132(3):433-435.

28. Ueno A, Hisatomi T, Enaida H, et al. Biocompatibility of brilliant blue $\mathrm{G}$ in a rat model of subretinal injection. Retina. 2007;27(4):499-504.

29. Steel DH, Chen Y, Latimer J, White K, Avery PJ. Does internal limiting membrane peeling size matter? J Vitreo Retinal Diseases. 2017; $1: 27-33$.
Clinical Ophthalmology

\section{Publish your work in this journal}

Clinical Ophthalmology is an international, peer-reviewed journal covering all subspecialties within ophthalmology. Key topics include: Optometry; Visual science; Pharmacology and drug therapy in eye diseases; Basic Sciences; Primary and Secondary eye care; Patient Safety and Quality of Care Improvements. This journal is indexed on

\section{Dovepress}

PubMed Central and CAS, and is the official journal of The Society of Clinical Ophthalmology (SCO). The manuscript management system is completely online and includes a very quick and fair peer-review system, which is all easy to use. Visit http://www.dovepress.com/ testimonials.php to read real quotes from published authors. 